\title{
Epoxidation of crotyl alcohol in the presence of titanium silicalite Ti-MWW catalyst - the new and friendly method of 2,3-epoxybutane-1-ol synthesis
}

\author{
Agnieszka Wróblewska*, Anna Fajdek, Eugeniusz Milchert \\ West Pomeranian University of Technology, Szczecin, Institute of Organic Chemical Technology, ul. Pułaskiego 10, \\ 70-322 Szczecin, Poland \\ *corresponding author: e-mail address: Agnieszka.Wroblewska@zut.edu.pl
}

\begin{abstract}
Epoxidation of crotyl alcohol (CA) with $30 \mathrm{wt} \%$ hydrogen peroxide over Ti-MWW catalyst has been studied with methanol as a solvent and at autogenic pressure. The influence of temperature in the range of $20-$ $120^{\circ} \mathrm{C}$, the molar ratio of $\mathrm{CA} / \mathrm{H}_{2} \mathrm{O}_{2}$ 1:1-5:1, methanol concentration $5-90 \mathrm{wt} \%$, Ti-MWW catalyst concentration $0.0-5.0 \mathrm{wt} \%$ and the reaction time $5-300 \mathrm{~min}$ have been studied. The main product of CA epoxidation is 2,3-epoxybutane-1-ol (2,3EB1O), a compound with many applications.
\end{abstract}

Keywords: Ti-MWW, crotyl alcohol epoxidation, 2,3-epoxybutane-1-ol.

\section{INTRODUCTION}

Epoxide compounds are valuable intermediates and final products of the organic chemical industry. Recently, much attention has been devoted to the improvement of the processes of epoxides synthesis to make them less hazardous for the natural environment and also new methods for their preparation are being developed. The changes rely on the elimination of organic wastes, byproducts difficult to manage and the limitation of the quantity of generated sewage and allow to replace dangerous and non-ecological stoichiometric syntheses with milder and one-step or non-solvent. An interesting alternative is, for example, utilization of hydrogen peroxide in the oxidation processes - the only by-product of hydrogen peroxide transformation is water. The utilization of titanium-silicalite catalysts in combination with hydrogen peroxide allows performing of many processes in mild conditions (at low temperatures and at atmospheric pressure), very often with high selectivity of epoxide compound and conversions of raw materials. These processes are more ecologically friendly than for example chlorine and other non-chlorine methods of epoxidations ${ }^{\mathbf{1}}$.

The main product of the epoxidation of crotyl alcohol (CA) is 2,3-epoxybutane-1-ol (2,3EB1O). The main part of its applications is connected with pharmaceutical industry - production of antibacterial macrolide and carbapeneme antibiotics ${ }^{2-4}$. 2,3-Epoxybutane-1-ol can be also used in the production of many products of natural origin: serricornin ${ }^{5}$, aplysiatoxin or dibromoaplysiatoxin6 and synthetic analogues with high biological and pharmaceutical importance such as cardiology drugs and biochemical probes ${ }^{7}$.

This paper presents the investigations of the epoxidation of CA towards 2,3-epoxybutane-1-ol with the use of a 30 wt $\%$ hydrogen peroxide under autogenic pressure and over the Ti-MWW catalyst.

\section{EXPERIMENTAL}

The Ti-MWW catalyst was synthesized by the method of Wu et al. ${ }^{8}$ The XRD pattern of the Ti-MWW catalyst (Figure 1a) was totally consistent with the XRD pattern of Ti-MWW presented in literature ${ }^{9}$. Scanning electron micrographs of the Ti-MWW catalyst is shown in Figure 1b. All the crystals appeared to be thin plates that mainly exhibited the hexagonal morphology. The thin plates of the Ti-MWW sample have approximately $2.5 \mu \mathrm{m}$ in length and $0.3 \mu \mathrm{m}$ in thickness and form aggregates. The IR was made using the $\mathrm{KBr}$ pellet technique and was the same as in literature9. The IR method is frequently employed to characterize the framework tetrahedral Ti in Ti-containing molecular sieves due to a characteristic band at 960 $\mathrm{cm}^{-1}$, which is assigned to the vibration of Si-O-Ti (Figure 1c). As shown in Fig. 1d, the UV-vis spectrum of TiMWW after acid treatment and calcination shows the main band at $260 \mathrm{~nm}$. The band confirms the presence of the $\mathrm{Ti}$ in tetrahedral coordination in the material. The other, additional bands were not observed. The investigations by X-ray microanalysis showed that the amount of $\mathrm{Ti}$ in the sample after crystallization was $5.68 \mathrm{wt} \%$, and after acid treatment and calcinations $-3.22 \mathrm{wt} \%$.

In the epoxidation of CA the following raw materials were used: crotyl alcohol (95 wt \%, Fluka), the Ti-MWW titanium silicalite catalyst, hydrogen peroxide $(30 \mathrm{wt} \%$ water solution, P.O.Ch. Gliwice, Poland) and methanol (analytical grade., P.O.Ch. Gliwice, Poland). Epoxidation of CA was carried out in an autoclave equipped with a Teflon inset of $7 \mathrm{~cm}^{3}$ in capacity. In order to make mass balances, the following analyses were made: unreacted hydrogen peroxide was iodometrically determined ${ }^{\mathbf{1 0}}$, the other products and the unreacted allyl alcohol were determined by gas chromatography. After the calculation of the mass balances, the main functions describing the process were determined: the selectivity of the transformation to 2,3EB1O in relation to CA consumed, the conversion of CA an hydrogen peroxide and the selectivity of transformation to organic compounds in relation to hydrogen peroxide consumed.

\section{RESULTS AND DISCUSSION}

Epoxidation of crotyl alcohol over titanium-silicalite Ti-MWW catalyst by a $30 \mathrm{wt} \%$ water solution of hydrogen peroxide in methanol as a solvent leads to 2,3-epoxybutane1 -ol as the main product. All the products of this process are presented in Figure 2.

The influence of temperature on crotyl alcohol epoxidation over Ti-MWW catalyst was investigated in the temperatures range of $20-120^{\circ} \mathrm{C}$. The initial param- 
a)

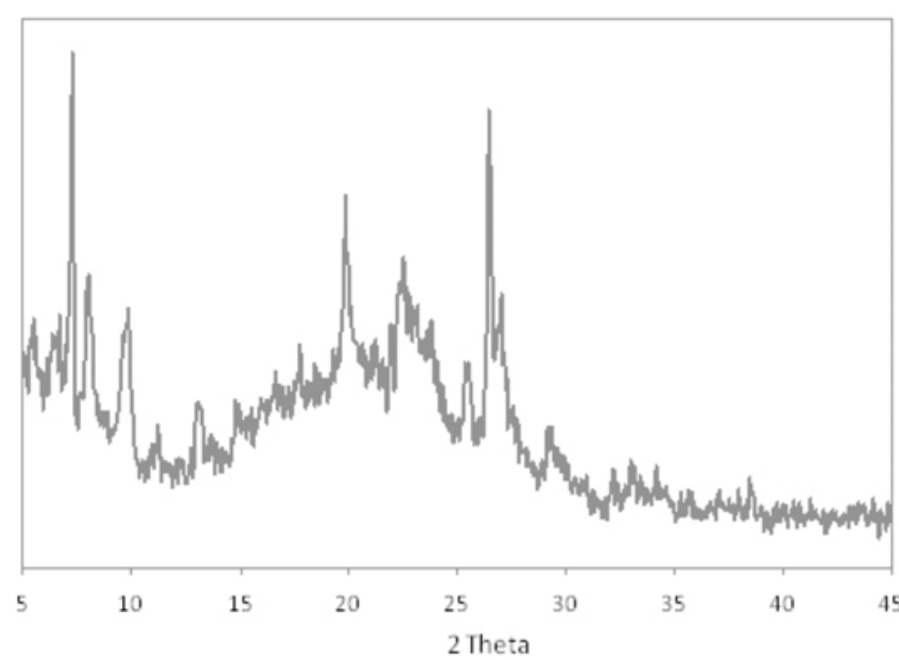

c)

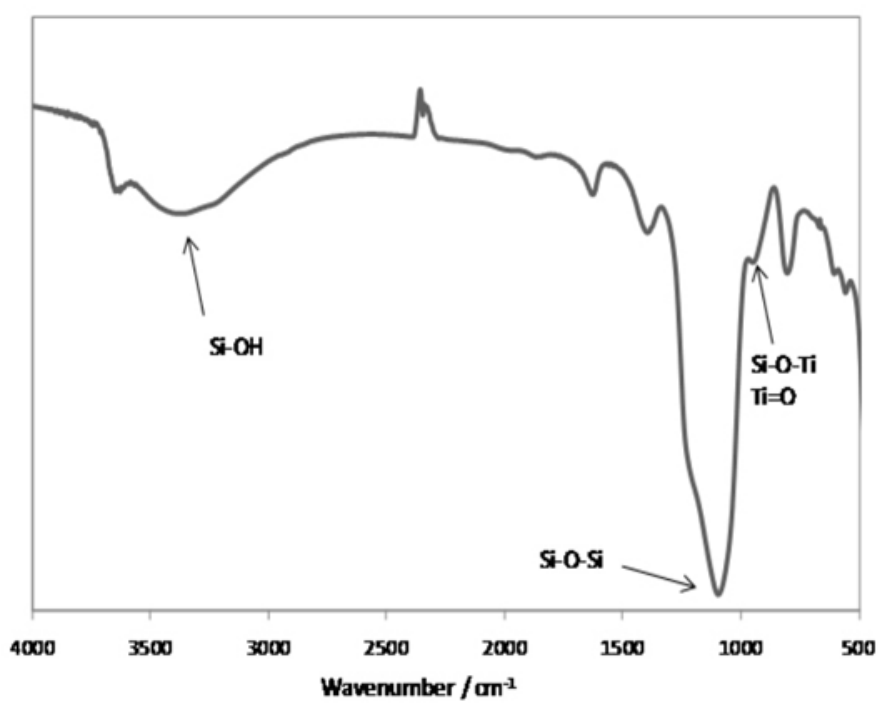

b)

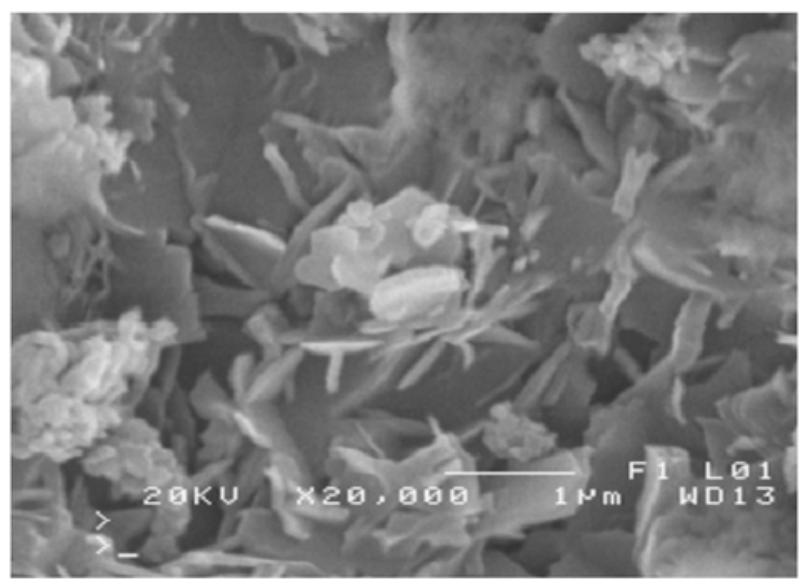

d)

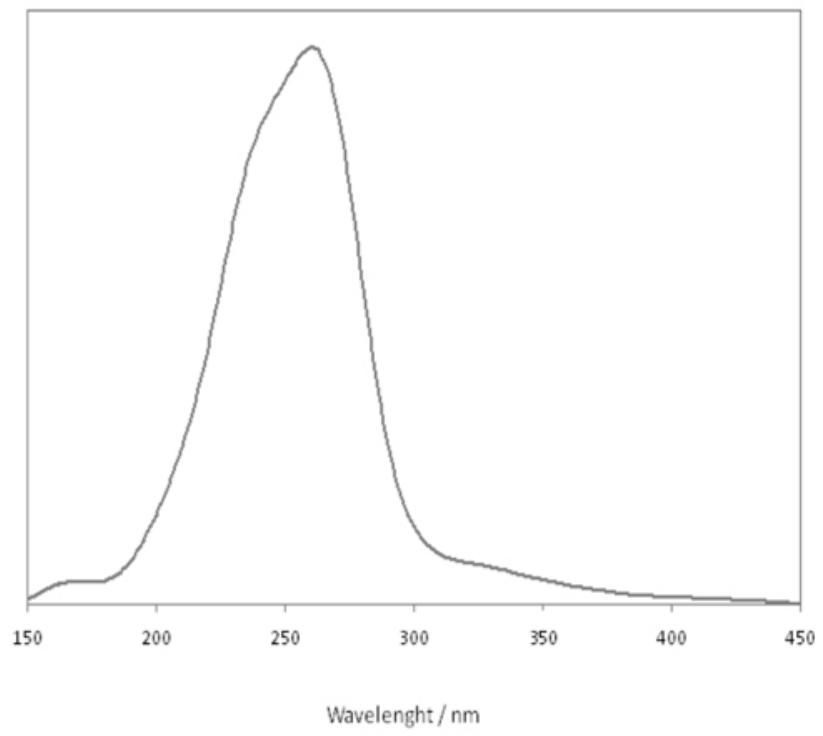

Figure 1. Characteristics of Ti-MWW catalyst: a) XRD pattern, b) scanning electron micrographs, c) IR spectra, d) UV-Vis spectra

eters were as follows: the molar ratio of $\mathrm{CA} / \mathrm{H} 2 \mathrm{O} 2=1: 1$, the concentration of methanol (solvent) of $40 \mathrm{wt} \%$, the concentration of Ti-MWW $2 \mathrm{wt} \%$, the reaction time 180 min and the intensity of stirring $500 \mathrm{rpm}$. The results are presented in Figure 3a. An increase in temperature from 20 to $40^{\circ} \mathrm{C}$ does not change the selectivity of transformation to 23EB1O in relation to CA consumed, which remains at a constant level of $100 \mathrm{~mol} \%$. At $60^{\circ} \mathrm{C}$, this selectivity of 23EB1O decreases, which is a consequence of 2,3-dimetoxybutane-1-ol production (selectivity 3 mol\%). At $80^{\circ} \mathrm{C}$ the selectivity of 2,3-dimetoxybutane-1ol amounts to $19 \mathrm{~mol} \%$ and also 1,2,3-butanotriol is formed (selectivity $4 \mathrm{~mol} \%$ ). The selectivities of these two by-products rise with the temperature, and at $120^{\circ} \mathrm{C}$ achieve values: $54 \mathrm{~mol} \%$ and $12 \mathrm{~mol} \%$, respectively. The selectivity of transformation to organic compounds in relation to $\mathrm{H}_{2} \mathrm{O}_{2}$ consumed increases from $42 \mathrm{~mol} \%$ to $47 \mathrm{~mol} \%$ in the temperature range of $20-120^{\circ} \mathrm{C}$. Changes in the conversion of CA are almost the same. The conversion of hydrogen peroxide is constant in the whole range of the investigated temperatures $(\sim 98 \mathrm{~mol} \%)$. Thus the optimum temperature of epoxidation is $40^{\circ} \mathrm{C}$, at this temperature the selectivity of transformation to $23 \mathrm{~EB} 1 \mathrm{O}$ in relation to CA consumed and the hydrogen peroxide conversion are high.

The influence of molar ratio $\mathrm{CA} / \mathrm{H}_{2} \mathrm{O}_{2}$ on crotyl alcohol epoxidation over Ti-MWW catalyst was investigated in the range of 1:1-5:1. The initial parameters were as follows: the temperature $40^{\circ} \mathrm{C}$, the concentration of methanol (solvent) of $40 \mathrm{wt} \%$, the concentration of Ti-MWW $2 \mathrm{wt} \%$, the reaction time $180 \mathrm{~min}$ and the intensity of stirring $350 \mathrm{rpm}$. The obtained results are presented in Figure $3 \mathrm{~b}$. The analysis of the dependencies presented in Fig. $3 \mathrm{~b}$ implies that the process should be performed at the molar ratios of $\mathrm{CA} / \mathrm{H}_{2} \mathrm{O}_{2}<2: 1$. The functions reach high values for the $\mathrm{CA} / \mathrm{H}_{2} \mathrm{O}_{2}$ ratio of 1:1. The selectivity of transformation to 23EB1O in relation to crotyl alcohol is constant $(100 \mathrm{~mol} \%)$ in the whole range of molar ratio studied. A significant decrease in the crotyl alcohol conversion from $42 \mathrm{~mol} \%$ at $\mathrm{CA} / \mathrm{H}_{2} \mathrm{O}_{2}=1: 1$ to $21 \mathrm{~mol} \%$ at 


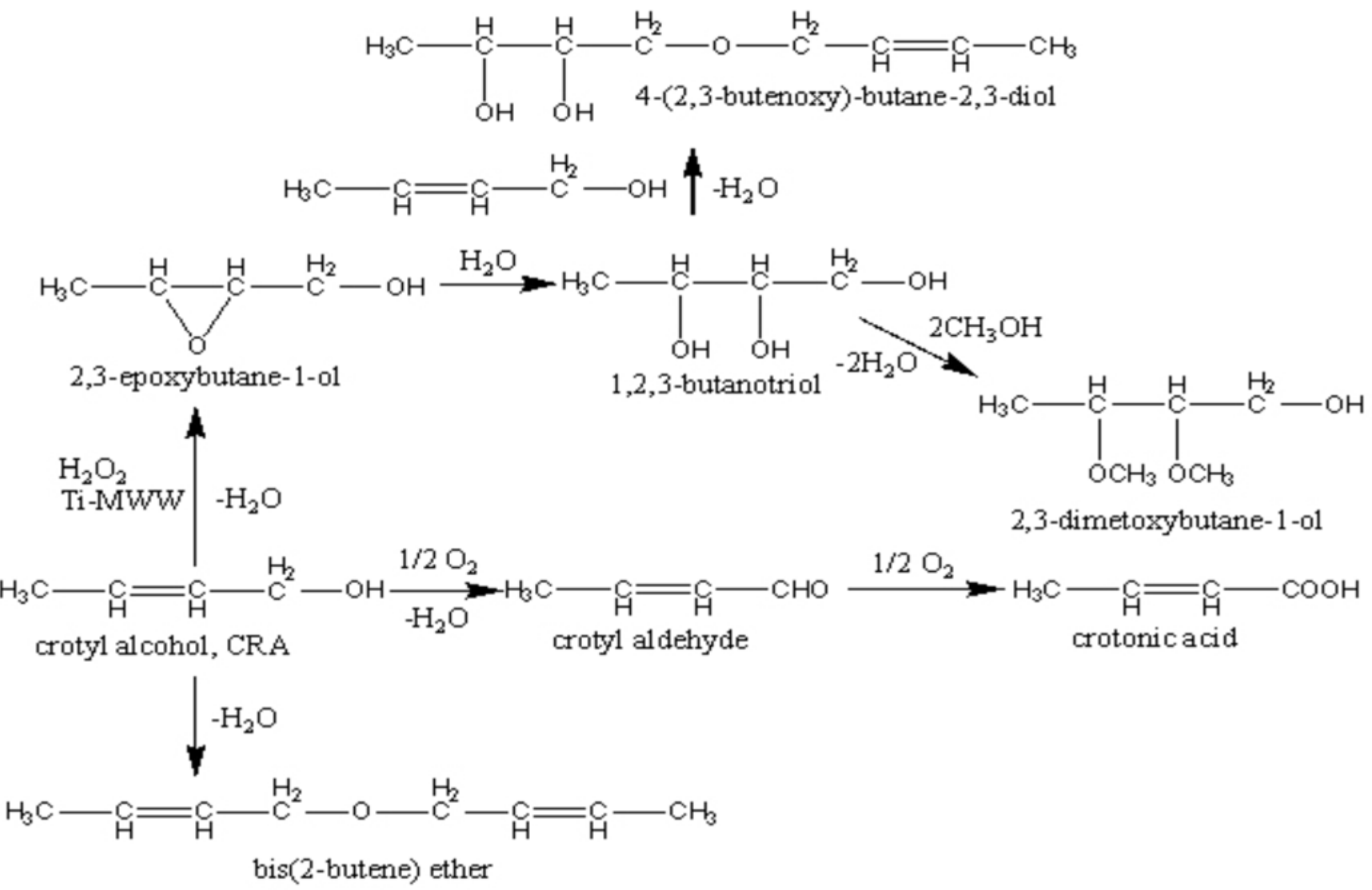

Figure 2. Reaction of the CA epoxidation process

$\mathrm{CA} / \mathrm{H}_{2} \mathrm{O}_{2}=5: 1$ is mainly a consequence of an increasing excess of CA with respect to $\mathrm{H}_{2} \mathrm{O}_{2}$ and the method of the calculation. At this stage of the investigation the equimolecular molar ratio of $\mathrm{CA} / \mathrm{H}_{2} \mathrm{O}_{2}$ was considered as the most beneficial.

The influence of solvent concentration (methanol) on crotyl alcohol epoxidation over the Ti-MWW catalyst was investigated in the range of $5-90 \mathrm{wt} \%$. The initial parameters were as follows: the temperature $40^{\circ} \mathrm{C}$, the molar ratio of $\mathrm{CA} / \mathrm{H}_{2} \mathrm{O}_{2}=1: 1$, the concentration of Ti-MWW $2 \mathrm{wt} \%$, the reaction time $180 \mathrm{~min}$ and the intensity of stirring $350 \mathrm{rpm}$. The results are presented in Figure 3c. The studies of the influence of methanol concentration on the course of CA epoxidation show that in the whole range of the investigated solvent concentrations the selectivity of epoxide compound achieves about $100 \mathrm{~mol} \%$. Only for methanol concentration $5 \mathrm{wt} \%$ the bis(2-butene) ether is formed (with selectivity $4 \mathrm{~mol} \%$ ). The conversion of CA reaches the maximal value at methanol concentration $40 \mathrm{wt} \%(42 \mathrm{~mol} \%)$, the same as the selectivity of transformation to organic compounds in relation to hydrogen peroxide consumed ( $42 \mathrm{~mol} \%)$. Then these functions do not change. Taking into account the obtained results the methanol concentration of $40 \mathrm{wt} \%$ was chosen as the most beneficial.

The influence of catalyst Ti-MWW concentration on crotyl alcohol epoxidation over Ti-MWW catalyst was investigated in the range of $0-5 \mathrm{wt} \%$. The initial parameters were as follows: the temperature $40^{\circ} \mathrm{C}$, the molar ratio of $\mathrm{CA} / \mathrm{H}_{2} \mathrm{O}_{2}=1: 1$, the concentration of methanol (solvent) of $40 \mathrm{wt} \%$, the reaction time $180 \mathrm{~min}$ and the intensity of stirring $350 \mathrm{rpm}$. The results are presented in Figure $3 \mathrm{~d}$. In the range of low concentrations of the cata- lyst Ti-MWW $(0-0.1 \mathrm{wt} \%)$, the selectivity of transformation to $23 \mathrm{~EB} 1 \mathrm{O}$ increases to $100 \mathrm{~mol} \%$. The only byproduct in this range of catalyst concentration is bis(2butene) ether (selectivity to $5 \mathrm{~mol} \%$ ). In the catalyst TiMWW concentration range $0-1.0 \mathrm{wt} \%$ the selectivity of transformation to organic compounds rapidly increases and reaches a maximum for the catalyst concentration 3 wt $\%$. Further increase in the catalyst concentration up to $3 \mathrm{wt} \%$ does not change the value of this function. The conversion of crotyl alcohol rapidly increases and reach at $3 \mathrm{wt} \%$ a maximum value of $43 \mathrm{~mol} \%$. Further increase in the catalyst concentration does not result in significant changes in this function. The optimum concentration of Ti-MWW is $3 \mathrm{wt} \%$.

The influence of reaction time on crotyl alcohol epoxidation over Ti-MWW catalyst was investigated in the range of 5-300 min. The initial parameters were as follows: the temperature $40^{\circ} \mathrm{C}$, the molar ratio of $\mathrm{CA} /$ $\mathrm{H}_{2} \mathrm{O}_{2}=1: 1$, the concentration of methanol (solvent) of $40 \mathrm{wt} \%$, the concentration of Ti-MWW $3 \mathrm{wt} \%$ and the intensity of stirring $350 \mathrm{rpm}$. The results are presented in Figure $3 \mathrm{e}$. Within the time from 5 to 15 minutes the selectivity of transformation to $2,3 \mathrm{~EB} 1 \mathrm{O}$ in relation to CA consumed increases to $100 \mathrm{~mol} \%$ and then its value remains at this constant level. In the first 15 minutes of the reaction the crotyl alcohol conversion and the selectivity of transformation to organic compounds in relation to the hydrogen peroxide consumed grow rapidly and in the range of $60-300$ min remain constant. The time of 30 min has been taken as the most beneficial reaction time.

The influence of the intensity of stirring on crotyl alcohol epoxidation over Ti-MWW catalyst was investigated 
a)

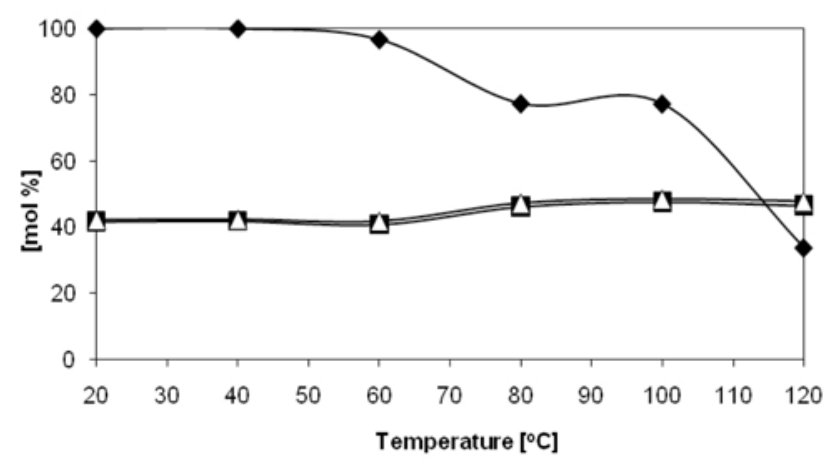

c)

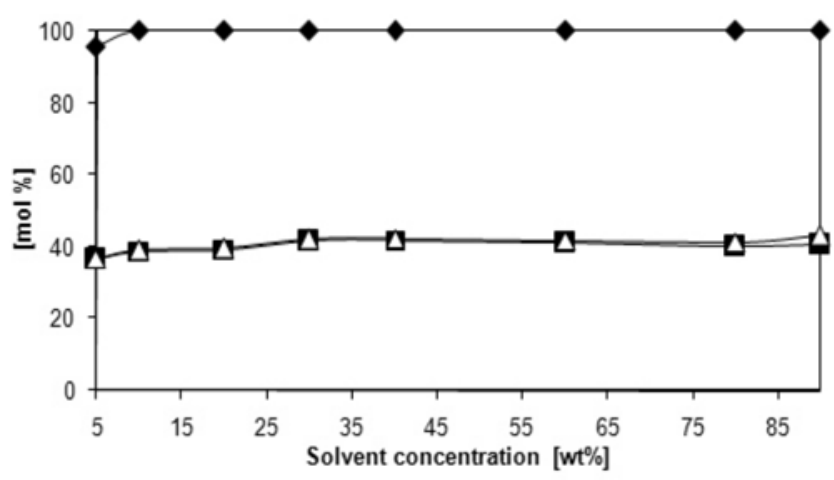

e)

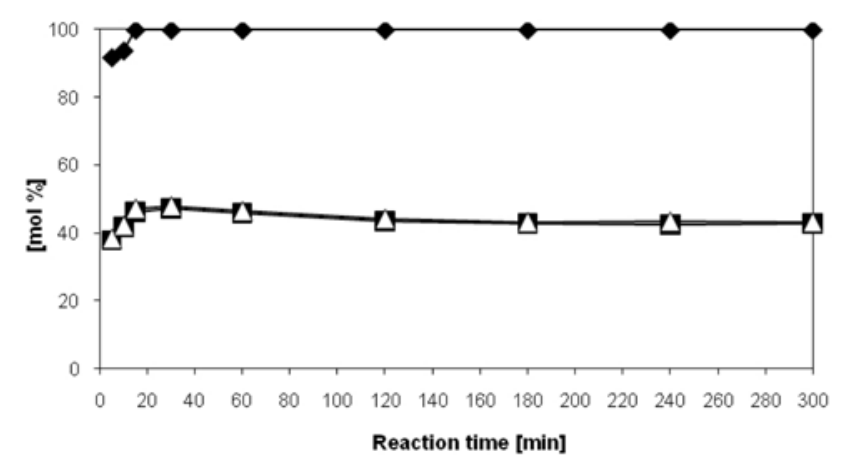

b)

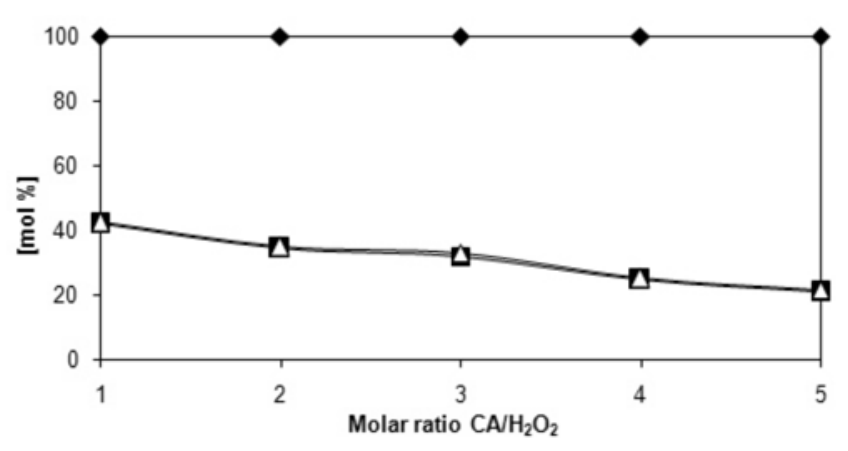

d)

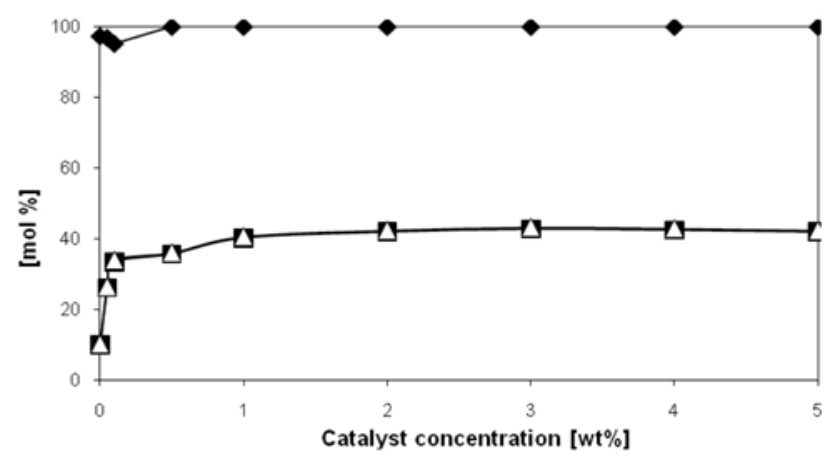

f)

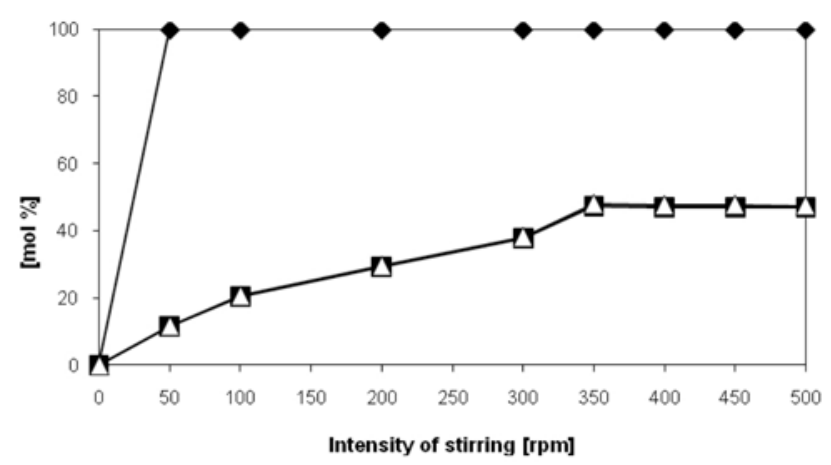

Figure 3. The influence of technological parameters on CA epoxidation over Ti-MWW catalyst: a) the influence of temperature $\left(\mathrm{CA} / \mathrm{H}_{2} \mathrm{O}_{2}=1: 1\right.$, methanol concentration $40 \mathrm{wt} \%$, catalyst concentration $2 \mathrm{wt} \%$, reaction time $3 \mathrm{~h}$, intensity of stirring $350 \mathrm{rpm}$ ), b) the influence of $\mathrm{CA} / \mathrm{H}_{2} \mathrm{O}_{2}$ molar ratio (temperature $40^{\circ} \mathrm{C}$, methanol concentration 40 wt $\%$, catalyst concentration $2 \mathrm{wt} \%$, reaction time $3 \mathrm{~h}$, intensity of stirring $350 \mathrm{rpm})$, c) the influence of the solvent concentration (methanol) (temperature $40^{\circ} \mathrm{C}, \mathrm{CA} / \mathrm{H}_{2} \mathrm{O}_{2}=1: 1$, catalyst concentration $2 \mathrm{wt} \%$, reaction time $3 \mathrm{~h}$, intensity of stirring $350 \mathrm{rpm}$ ), d) the influence of the catalyst Ti-MWW concentration (temperature $40^{\circ} \mathrm{C}, \mathrm{CA} / \mathrm{H}_{2} \mathrm{O}_{2}=1: 1$, methanol concentration $40 \mathrm{wt} \%$, reaction time $3 \mathrm{~h}$, intensity of stirring $350 \mathrm{rpm}$ ), e) the influence of the reaction time (temperature $40^{\circ} \mathrm{C}, \mathrm{CA} / \mathrm{H}_{2} \mathrm{O}_{2}=1: 1$, methanol concentration $40 \mathrm{wt} \%$, catalyst concentration $3 \mathrm{wt} \%$, reaction time $3 \mathrm{~h}$, intensity of stirring $350 \mathrm{rpm}$ ), f) the influence of the intensity of stirring (temperature $40^{\circ} \mathrm{C}, \mathrm{CA} / \mathrm{H}_{2} \mathrm{O}_{2}=1: 1$, methanol concentration $40 \mathrm{wt} \%$, catalyst concentration $3 \mathrm{wt} \%$, reaction time $30 \mathrm{~min}$ ): - - selectivity of transformation to 2,3EB1O in relation to CA consumed, a - conversion of CA, $\mathbf{-}-$ selectivity of transformation to organic compounds in relation to hydrogen peroxide consumed

in the range of $0-500 \mathrm{rpm}$. The initial parameters were as follows: the temperature $40^{\circ} \mathrm{C}$, the molar ratio of $\mathrm{CA} /$ $\mathrm{H}_{2} \mathrm{O}_{2}=1: 1$, the concentration of methanol (solvent) of $40 \mathrm{wt} \%$, the concentration of Ti-MWW $3 \mathrm{wt} \%$ and the reaction time $30 \mathrm{~min}$. The results are presented in Figure 3f. Analysis of the influence of the intensity of stirring on the selectivity of transformation to 23EB1O has shown an increase in this function to $50 \mathrm{rpm}$, and next the value of this function is constant. The character of the changes of crotyl alcohol conversion and selectivity of transforma- tion to organic compounds in relation to the hydrogen peroxide consumed with increasing intensity of stirring is similar, these functions reach the highest values for intensity of stirring of $350 \mathrm{rpm}(47 \mathrm{~mol} \%)$. The intensity of stirring $350 \mathrm{rpm}$ has been taken as the most beneficial.

\section{CONCLUSIONS}

The process of crotyl alcohol epoxidation over the titanium silicalite Ti-MWW catalyst under autogenic pres- 
sure has been found to be most effective when it is conducted at the temperature of $40^{\circ} \mathrm{C}$, the molar ratio of $\mathrm{CA} /$ $\mathrm{H}_{2} \mathrm{O}_{2}=1: 1$, methanol concentration of $40 \mathrm{wt} \%$, the catalyst concentration of $3 \mathrm{wt} \%$, during the reaction time of $30 \mathrm{~min}$, and with the intensity of stirring $350 \mathrm{rpm}$. In these conditions the selectivity of transformation to 2,3EB1O in relation to CA consumed is $100 \mathrm{~mol} \%$, the CA conversion reaches $47 \mathrm{~mol} \%$ and the selectivity of transformation to organic compounds in relation to hydrogen peroxide consumed is $47 \mathrm{~mol} \%$.

\section{LITERATURE CITED}

1. Podraża, A., Łukasiewicz \& M., Pielichowski, J. (2004). The application of urine-hydroperoxide complex in oxidation reactions of organic compounds. Przem. Chem. 83, $429-433$ (in Polish).

2. Schumacher, K. \& Ravikovitch, P. (2000). Characterization of MCM-48 material. Am. Chem. Soc. 16, 4648 - 4654. DOI: $10.1021 / 1 a 991595 i$.

3. Thomas, J. M. \& Raja, R. (2006). Innovations in Oxidation Catalysis Leading to a Sustainable Society. Catal. Today 117, 22 - 31. DOI: 10.1016/j.cattod.2006.05.003.

4. Raczko, J. (2003). From Furan to Open-chain Systems. Synthesis of C1-C9 Fragment of Tylonolide. Tetrahedron 59, 10181 - 10186. DOI: 10.1016/j.tet.2003.10.17.

5. Kobayashi, Y. \& Kitano, Y. (1986). Diastereo- and Enantioselective Preparation of $\beta$-alkylhomoallylic Alcohols Synthesis of Serricornin and Corynomycolic Acid. Tetrahedron $42,2937-2943$.

6. Okumura, H., Kuroda, S., Tomita, K. (1991). Synthesis of Polysiatoxin: Stereoselective Synthesis of Key Fragments. Tetrahedron Lett. 32, 5137 - 5140.

7. Hanson, R. M. (1991). The Synthetic Methodology of Nonracemic Glycidol and Related 2,3-epoxy Alcohols. Chem. Rev. 91, 437 - 475. DOI: 10,1021/cr00004a001.

8. Song, F., Liu, Y., Wu, H., He, M. (2006). A novel titanosilicate with MWW structure: Highly effective liquidphase ammoximation of cycloheksanone. J. Catal. 237(2), 359 - 367. DOI: 10.1016/j.cat.2005.11.018.

9. Taramasso, M., Perego, G. \& Notari, B. (1983). Preparation of porous crystalline synthetic material comprised of silicon and titanium oxides. US Pat. 4410501.

10. Reddy, J.S., Kumar, R. \& Ratnasamy, P. (1990). Titanium silicalite-2: synthesis, characterization and catalytic properties. Appl. Catal. 58, L1-L4. 